\title{
Cálcio, fósforo e proteína total no sangue de frangos de corte em função de níveis de balanço eletrolítico da ração
}

\author{
[Calcium, phosphorus and total protein in blood of broiler according to levels \\ of electrolytic balance in rations]
}

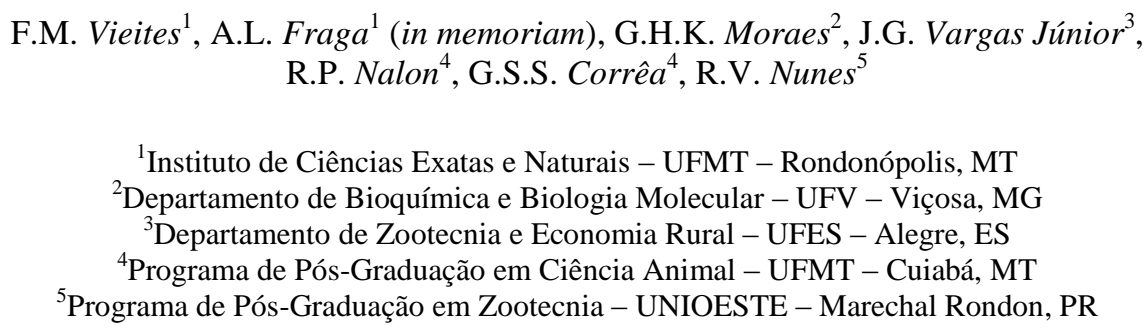

\section{RESUMO}

Determinaram-se os melhores valores do balanço eletrolítico (BE) de dietas para frangos quanto aos teores de cálcio, fósforo e proteína total no sangue de frangos de corte aos 42 dias de idade. Foram utilizadas 1728 aves de marca comercial, machos. As aves foram alimentadas com duas dietas basais, 20 ou $23 \%$ de proteína bruta (PB), na fase inicial, e uma única ração basal, $20 \%$ de $\mathrm{PB}$, na fase de crescimento, combinadas com níveis de balanço eletrolítico de $0 ; 50 ; 100 ; 150 ; 200 ; 250 ; 300$ e $350 \mathrm{mEq} / \mathrm{kg}$. Foi utilizado delineamento experimental inteiramente ao acaso, em arranjo fatorial, com seis repetições de 18 aves cada e 96 unidades experimentais. Foi escolhida uma ave em cada unidade experimental para a coleta de sangue. Foram avaliados os teores de cálcio, fósforo e proteínas totais no sangue dessas aves aos 42 dias de idade. Os melhores valores de BE estimados para o teor de proteína total no sangue foram de 101 e $131 \mathrm{mEq} / \mathrm{kg}$ da dieta, para planos nutricionais de $20-20 \%$ e $23-20 \%$ de PB, respectivamente. Para os teores plasmáticos de cálcio e fósforo, não foram encontradas diferenças entre os níveis de BE estudados.

Palavras-chave: avicultura industrial, equilíbrio eletrolítico, homeostasia, minerais, plasma

\begin{abstract}
The best values of electrolytic balance (EB) in diets for blood levels of calcium, phosphorus and total protein for 42 days old broiler chickens was determined. 1728 Ross male chicks were used, which were fed with two basal diets with 20 or $23 \%$ of crude protein $(C P)$ in the initial phase and one basal diet with $20 \%$ of CP during growing phase. They were combined with the following EB levels: 0; 50; 100; 150; 200; 250; 300 and 350mEq/kg. A completely randomized design with a factorial arrangement of treatments was used with six repetitions of 18 birds and 96 experimental units. One bird was chosen from each experimental unit for blood collection. The content of calcium, phosphorus and total protein in the blood of these birds at 42 days of age was evaluated. The best values of EB for the nutritional plans of 20-20\% and for 23-20\% were 101 and $131 \mathrm{mEq} / \mathrm{kg}$ of crude protein, respectively. Significant differences were not found among the EB studied for the serum concentrations of calcium and phosphorus levels.
\end{abstract}

Keywords: poultry industry, electrolytic equilibrium, homeostasis, minerals, plasma

Recebido em 10 de março de 2010

Aceito em 8 de junho de 2011

E-mail: fmvieites@yahoo.com.br

Projeto de Pesquisa Financiado pelo CNPq 


\section{INTRODUÇÃO}

O sangue do animal transporta nutrientes do trato digestivo para os tecidos, os produtos finais do metabolismo das células até os órgãos de excreção, o oxigênio dos pulmões para os tecidos, o dióxido de carbono dos tecidos para os pulmões e as secreções das glândulas endócrinas por todo o corpo. O sangue também ajuda a regular a temperatura corporal, mantém constante a concentração de água e de eletrólitos nas células, regula a concentração do íon hidrogênio e defende o corpo contra microrganismos (Swenson, 2006). Os constituintes extracelulares do sangue incluem a água, os eletrólitos, as proteínas, a glicose, as enzimas e os hormônios. Dentre os eletrólitos, merecem destaque o cálcio dissociado $\left(\mathrm{Ca}^{2+}\right)$ e o fosfato $\left(\mathrm{PO}_{4}{ }^{2-}\right)$.

O cálcio plasmático pode ser encontrado ligado a proteínas (albumina, globulina), a outros compostos orgânicos e também a fosfatos e a outros ânions, sendo que metade de sua forma biodisponível se encontra dissociada (Vieites et al., 2004). A concentração de cálcio sanguíneo é mantida em limites sensíveis pela ação de alguns hormônios que controlam a absorção, a excreção e o metabolismo ósseo, como os hormônios paratireoideo e tirocalcitonina (Macari et al., 2002). Este cálcio plasmático é essencial para a coagulação sanguínea, permeabilidade de membrana, excitabilidade neuromuscular, transmissão do impulso nervoso e ativação de sistemas enzimáticos.

O fosfato une-se ao cálcio formando compostos que conferem rigidez aos ossos, participa do metabolismo energético, metabolismo de carboidratos, aminoácidos e gordura, nos processos químicos do sangue, crescimento do esqueleto, transporte de ácidos graxos e outros lipídios. Participa também como constituinte de ácidos nucleicos, e componentes de muitas coenzimas, além de estar envolvido no armazenamento e na transferência de energia em compostos fosforilados da glicose e seus derivados (McDowell, 1992).

As proteínas plasmáticas são responsáveis pela manutenção da pressão coloidosmótica do plasma, contribuindo, assim, para a manutenção da pressão sanguínea dentro dos limites normais. Além disso, ajudam a regular o equilíbrio ácido- base do sangue e participam do transporte de nutrientes $(\mathrm{Ca}, \mathrm{P}, \mathrm{Fe}, \mathrm{Cu}$, lipídios, vitaminas lipossolúveis, aminoácidos), hormônios, colesterol, bilirrubina e outras substâncias (Swenson, 2006).

O equilíbrio ácido-básico (EAB) ou balanço eletrolítico (BE) define-se como a diferença entre os principais cátions e ânions da dieta. O equilíbrio ácido-básico refere-se à tendência de o animal manter constante a concentração de prótons $(\mathrm{H}+)$ intra e extracelular (Patience, 1990), e as funções metabólicas das células estão intimamente relacionadas com estas concentrações. Por essa razão, a regulação da concentração desse íon constitui um dos aspectos mais importantes da homeostasia. De acordo com Macari et al. (2002), a manutenção do equilíbrio ácido-básico do meio interno tem grande importância fisiológica e bioquímica, uma vez que as atividades das enzimas celulares, as trocas eletrolíticas e a manutenção do estado estrutural das proteínas do organismo são influenciadas por pequenas alterações no $\mathrm{pH}$ sanguíneo.

A susceptibilidade das aves ao estresse calórico aumenta à medida que o binômio umidade relativa - temperatura ambiente ultrapassa a zona de conforto térmico, dificultando, assim, a dissipação de calor e incrementando a temperatura corporal, com efeito negativo sobre o desempenho da ave. Uma das consequências do estresse é a mudança no equilíbrio ácido-base com o aparecimento da alcalose respiratória.

Entre as respostas fisiológicas compensatórias das aves, quando expostas ao calor, inclui-se a vasodilatação periférica, resultando em aumento de perda de calor não evaporativo. Essa perda de calor pode também ocorrer com o aumento da produção de urina, se esta perda de água for compensada pelo maior consumo de água fria. Outra resposta fisiológica é o aumento na taxa respiratória, resultando em perdas excessivas de dióxido de carbono $\left(\mathrm{CO}_{2}\right)$. Assim, a pressão parcial de $\mathrm{CO}_{2}\left(\mathrm{pCO}_{2}\right)$ diminui, levando à queda na concentração de ácido carbônico (H2CO3) e hidrogênio $\left(\mathrm{H}^{+}\right)$. Em resposta, os rins aumentam a excreção de $\mathrm{HCO}_{3}{ }^{-}$e reduzem a excreção de $\mathrm{H}^{+}$ na tentativa de manter o equilíbrio ácido-base da ave (Borges et al., 2003). 
O objetivo do presente trabalho foi determinar o melhor valor de $\mathrm{BE}$ em dietas com dois planos nutricionais, $20-20 \%$ e $23-20 \%$ PB, para frangos de corte aos 42 dias de idade, com base nos teores de cálcio, fósforo e proteína total plasmática.

\section{MATERIAL E MÉTODOS}

O trabalho teve a duração de 42 dias e o abate das aves e a coleta de sangue foram feitos no próprio local do experimento. Foram utilizados 1728 frangos, machos, da marca comercial Ross, durante o período experimental, que compreendeu a fase inicial de 1 a 21 dias e a fase de crescimento de 22 a 42 dias. Foram distribuídos uniformemente no início do experimento em 96 boxes. Duas dietas basais foram fornecidas na fase inicial, com 20 e $23 \%$ $\mathrm{PB}$, e apenas uma na fase de crescimento, com $20 \% \mathrm{~PB}$, caracterizando os planos nutricionais $20-20 \%$ e $23-20 \%$ PB.
As aves foram alojadas em galpão de alvenaria em boxes de $1,25 \times 1,80 \mathrm{~m}\left(2,25 \mathrm{~m}^{2}\right)$. Durante o período experimental, foi adotado programa contínuo de luz - 24 horas de luz natural + artificial. Para aquecimento dos pintos, do primeiro ao $15^{\circ}$ dia, foram utilizadas lâmpadas de infravermelho de 250W/box, com altura regulável.

As variáveis ambientais, temperatura e umidade relativa do ar, foram medidas com termômetros de máxima e mínima, termômetro de bulbo seco e úmido e termômetro de globo negro para obtenção do índice de temperatura de globo e umidade (ITGU). A temperatura do galpão foi registrada diariamente, e as leituras foram feitas às $7 \mathrm{e}$ às $19 \mathrm{~h}$ por termômetros de máxima e mínima. As leituras dos termômetros das demais variáveis foram realizadas cinco vezes ao dia, às 7, 10, 13, 16 e 19 h (Tab. 1).

Tabela 1. Temperatura, umidade relativa e índice de temperatura de globo e umidade (ITGU) registradas no período de 1 a 42 dias de idade

\begin{tabular}{|c|c|c|c|c|c|c|}
\hline \multirow{3}{*}{ Período (dias) } & \multicolumn{4}{|c|}{ Temperatura $\left({ }^{\circ} \mathrm{C}\right)$} & \multirow{3}{*}{ Umidade (\%) } & \multirow{3}{*}{ ITGU } \\
\hline & \multicolumn{2}{|c|}{ Máxima } & \multicolumn{2}{|c|}{ Mínima } & & \\
\hline & Absoluta & Média & Absoluta & Média & & \\
\hline 1 a 7 & 31 & 30 & 18 & 20 & $67 \pm 5,9$ & $74 \pm 0,9$ \\
\hline 8 a 14 & 32 & 30 & 18 & 22 & $71 \pm 6,1$ & $75 \pm 1,0$ \\
\hline 15 a 21 & 30 & 29 & 14 & 18 & $61 \pm 3,5$ & $73 \pm 1,7$ \\
\hline 22 a 28 & 28 & 27 & 19 & 21 & $64 \pm 8,7$ & $73 \pm 0,8$ \\
\hline 29 a 35 & 32 & 30 & 20 & 21 & $79 \pm 6,7$ & $76 \pm 2,0$ \\
\hline 36 a 42 & 32 & 28 & 21 & 22 & $83 \pm 8,6$ & $75 \pm 1,7$ \\
\hline Média & - & 29 & - & 21 & $73 \pm 6,6$ & $74 \pm 1,3$ \\
\hline
\end{tabular}

ITGU $=$ Tgn $+6,36$ Tpo $-330,08$.

Tgn = temperatura de globo negro $\left({ }^{\circ} \mathrm{K}\right)$; Tpo = temperatura de ponto de orvalho $\left({ }^{\circ} \mathrm{K}\right)$.

No período de 1 a 21 dias de idade, as aves receberam dietas com 20 e $23 \%$ de $\mathrm{PB}$ e, no período de 22 a 42 dias, uma única dieta basal com $20 \%$ de PB. Ambas foram elaboradas com milho, farelo de soja e glúten de milho, de forma a atender às recomendações nutricionais para as fases iniciais e de crescimento, exceto para potássio e cloro (Rostagno, 2000). As dietas foram formuladas de modo a conter $\mathrm{BE}$ de $150 \mathrm{mEq} / \mathrm{kg}$ utilizando-se do cloreto de amônio para esse ajuste (Tab. 2).

Os valores de BE foram calculados segundo fórmula proposta por Mongin (1981): $\mathrm{BE}=$ $\left(\% \mathrm{Na}^{+} \times 100 / 22,990^{*}\right)+\left(\% \mathrm{~K}^{+}\right.$x $\left.100 / 39,098^{*}\right)-$ $\left(\% \mathrm{Cl}^{-} \mathrm{x} 100 / 35,453^{*}\right)$, em que representa o equivalente grama do $\mathrm{Na}^{+}, \mathrm{K}^{+}$ou $\mathrm{Cl}^{-}$, respectivamente.

Foi utilizado delineamento experimental inteiramente ao acaso, em esquema fatorial $8 \times 2$ (oito níveis de BE dentro de duas sequências proteicas), seis repetições e 18 aves por unidade experimental. As dietas basais nas fases iniciais e de crescimento foram suplementadas com cloreto de amônio $\left(\mathrm{NH}_{4} \mathrm{Cl}\right)$ ou carbonato de potássio $\left(\mathrm{K}_{2} \mathrm{CO}_{3}\right)$ em substituição ao material inerte, de forma a obter oito níveis: $0 ; 50 ; 100 ; 150 ; 200$; 250; 300 e $350 \mathrm{mEq} / \mathrm{kg}$ de BE. As aves foram distribuídas uniformemente com um dia de idade e com média de peso de $45 \mathrm{~g}$. 
Vieites et al.

Tabela 2. Dietas basais iniciais com 20 e $23 \%$ de proteína bruta (PB) e dieta basal de crescimento

\begin{tabular}{|c|c|c|c|}
\hline Ingrediente & $\begin{array}{l}\text { Inicial } \\
(20 \% \mathrm{~PB})\end{array}$ & $\begin{array}{l}\text { Inicial } \\
(23 \% \text { PB })\end{array}$ & $\begin{array}{l}\text { Crescimento } \\
(20 \% \mathrm{~PB})\end{array}$ \\
\hline Milho & 60,870 & 55,913 & 61,785 \\
\hline Farelo de soja & 30,128 & 28,853 & 25,582 \\
\hline Farelo de glúten de milho & --------- & 7,941 & 4,100 \\
\hline Óleo de soja & 2,571 & 1,632 & 2,998 \\
\hline Calcário & 1,000 & 1,027 & 0,957 \\
\hline Fosfato bicálcico & 1,860 & 1,826 & 1,629 \\
\hline DL - metionina (99\%) & 0,285 & 0,130 & 0,163 \\
\hline $\mathrm{L}-\operatorname{arginina}(99 \%)$ & 0,097 & - & 0,153 \\
\hline Glicina & 0,296 & - & - \\
\hline $\mathrm{L}-$ lisina $\mathrm{HCl}(98 \%)$ & 0,332 & 0,295 & 0,308 \\
\hline $\mathrm{L}-$ treonina $(98,5 \%)$ & 0,139 & 0,007 & - \\
\hline $\mathrm{L}-$ triptofano & 0,012 & - & 0,006 \\
\hline Sal comum $(\mathrm{NaCl})$ & 0,469 & 0,291 & 0,392 \\
\hline Cloreto de amônio & 0,122 & 0,095 & 0,129 \\
\hline Cloreto de colina (60\%) & 0,100 & 0,100 & 0,100 \\
\hline Mistura vitamínica $^{1}$ & 0,100 & 0,100 & 0,100 \\
\hline Mistura mineral $^{2}$ & 0,050 & 0,050 & 0,050 \\
\hline Virginamicina $^{3}$ & 0,050 & 0,050 & 0,050 \\
\hline Anticoccidiano ${ }^{4}$ & 0,055 & 0,055 & 0,055 \\
\hline Antioxidante $^{5}$ & 0,010 & 0,010 & 0,010 \\
\hline Areia lavada (inerte) & 1,500 & 1,500 & 1,500 \\
\hline Total & 100,00 & 100,00 & 100,00 \\
\hline \multicolumn{4}{|c|}{ Composição calculada } \\
\hline Energia metabolizável (kcal/kg) & 3.000 & 3.000 & 3.000 \\
\hline Proteína bruta $(\%)$ & 20,00 & 23,00 & 20,00 \\
\hline Cálcio (\%) & 0,960 & 0,960 & 0,874 \\
\hline Fósforo total (\%) & 0,668 & 0,679 & 0,603 \\
\hline Fósforo disponível (\%) & 0,450 & 0,450 & 0,406 \\
\hline Sódio $(\%)$ & 0,225 & 0,222 & 0,192 \\
\hline Potássio (\%) & 0,737 & 0,712 & 0,663 \\
\hline Cloro (\%) & 0,484 & 0,457 & 0,366 \\
\hline Arginina total $(\%)$ & 1,324 & 1,321 & 1,250 \\
\hline Arginina digestível (\%) & 1,260 & 1,260 & 1,178 \\
\hline Glicina + serina $(\%)$ & 2,096 & 2,096 & 1,808 \\
\hline Metionina + cistina total $(\%)$ & 0,890 & 0,901 & 0,817 \\
\hline Metionina+cistina digestível (\%) & 0,815 & 0,815 & 0,741 \\
\hline Lisina total $(\%)$ & 1,250 & 1,252 & 1,148 \\
\hline Lisina digestível $(\%)$ & 1,143 & 1,143 & 1,045 \\
\hline Treonina total $(\%)$ & 0,874 & 0,873 & 0,746 \\
\hline Treonina digestível (\%) & 0,766 & 0,766 & 0,650 \\
\hline Triptofano total $(\%)$ & 0,245 & 0,243 & 0,746 \\
\hline Triptofano digestível (\%) & 0,221 & 0.221 & 0,650 \\
\hline Balanço eletrolítico $(\mathrm{mEq} / \mathrm{kg})$ & 150 & 150 & 150 \\
\hline
\end{tabular}

${ }^{1}$ Rovimix (Roche) -Níveis de garantia por quilo do produto: Vit. A - 10.000.000UI; Vit. D3 - 2.000.000UI; Vit. E 30.000UI; Vit. B1 - 2,0g; Vit. B6 - 4,0g; Ác. Pantotênico - 12,0g; Biotina - 0,10g; Vit. K3 - 3,0g; Ácido fólico 1,0g; Ácido nicotínico - 50,0g; Vit. B12 - 15.000mcg; Selênio - 0,25g; Veículo qsp $=1.000 \mathrm{~g}$.

${ }^{2}$ Roligomix (Roche). Níveis de garantia por quilo de produto: $\mathrm{Mn}-16,0 \mathrm{~g} ; \mathrm{Fe}-100,0 \mathrm{~g} ; \mathrm{Zn}-100,0 \mathrm{~g} ; \mathrm{Cu}-20,0 \mathrm{~g}$; Co

$-2,0 \mathrm{~g} ; \mathrm{I}-2,0 \mathrm{~g}$; Veículo q.s.p. $-1.000 \mathrm{~g}$.

${ }^{3} \mathrm{Stafac}^{\circledR}-50 \%$.

${ }^{4} \operatorname{Coxistac}^{\circledR}$ (Salinomicina) $-12 \%$.

${ }^{5}$ BHT (2,6-di-terc-butil-4-metil-fenol). 
$\mathrm{O} \mathrm{NH}_{4} \mathrm{Cl}$ foi utilizado para se obter os balanços de 0,50 e $100 \mathrm{mEq} / \mathrm{kg}$, e o $\mathrm{K}_{2} \mathrm{CO}_{3}$ para balanços de 200, 250, 300 e $350 \mathrm{mEq} / \mathrm{kg}$. Os tratamentos experimentais são apresentados na Tab. 3 .

O sangue de uma ave com peso médio de cada unidade experimental, coletado por punção cardíaca no $42^{\circ}$ dia de idade, foi colocado em tubos de ensaio e centrifugado, posteriormente, durante cinco minutos a 1500rpm, para a separação do soro, que foi imediatamente congelado. Foram feitas análises de $\mathrm{Ca}$, de $\mathrm{P}$ e de proteína total no soro, utilizando-se kits comerciais (In Vitro Diagnóstica).

Análises de variância e de regressão foram realizadas usando-se o programa SAEG (Sistema..., 1997), adotando-se $\mathrm{P}=5 \%$ na comparação de médias. Por interesse do estudo, optou-se pelo desdobramento do BE dentro de cada nível proteico, independentemente de a interação ter sido significativa.

Tabela 3. Tratamentos constituídos pelas dietas basais com 20 e $23 \%$ de proteína bruta (PB) e dieta basal de crescimento, suplementadas com $\mathrm{NH}_{4} \mathrm{Cl}$ ou $\mathrm{K}_{2} \mathrm{CO}_{3}$

\begin{tabular}{ccccc}
\hline $\mathrm{BE}(\mathrm{mEq} / \mathrm{kg})$ & Basal $(\mathrm{kg})$ & Inerte $(\mathrm{kg})$ & $\mathrm{NH}_{4} \mathrm{Cl}(\mathrm{kg})$ & $\mathrm{K}_{2} \mathrm{CO}_{3}(\mathrm{~kg})$ \\
\hline 0 & 98,5 & 0,693 & 0,807 & - \\
50 & 98,5 & 0,962 & 0,538 & - \\
100 & 98,5 & 1,231 & 0,269 & - \\
150 & 98,5 & 1,500 & - & - \\
200 & 98,5 & 1,151 & - & 0,349 \\
250 & 98,5 & 0,802 & - & 0,698 \\
300 & 98,5 & 0,453 & - & 1,047 \\
350 & 98,5 & 0,104 & - & 1,396 \\
\hline
\end{tabular}

$\mathrm{NH}_{4} \mathrm{Cl}-$ massa molar $(\mathrm{MM})=53,45$; pureza 99,5\%; $\mathrm{K}_{2} \mathrm{CO}_{3}-$ massa molar $(\mathrm{MM})=138,20$; pureza 99,0\%; $\mathrm{BE}-$ balanço eletrolítico.

\section{RESULTADOS E DISCUSSÃO}

O BE influenciou os níveis de cálcio e proteína total no soro sanguíneo das aves aos 42 dias de idade (Tab. 4). Os valores de fósforo apresentaram-se bem próximos à média, que foi de 6,52 e $6,78 \mathrm{mg} / \mathrm{dL}$ para as aves que receberam os planos nutricionais $20-20 \%$ PB e $23-20 \%$ PB, respectivamente.

Tabela 4. Valores plasmáticos de fósforo, cálcio e proteína total em frangos de corte de acordo com o balanço eletrolítico (BE)

\begin{tabular}{|c|c|c|c|c|c|c|}
\hline \multirow[b]{2}{*}{$\mathrm{BE}$} & \multicolumn{2}{|c|}{ Fósforo (mg/dL) } & \multicolumn{2}{|c|}{ Cálcio (mg/dL) } & \multicolumn{2}{|c|}{ Proteína total $(\mathrm{mg} / \mathrm{dL})$} \\
\hline & $20-20 \%$ & $23-20 \%$ & $20-20 \%$ & $23-20 \%$ & $20-20 \%$ & $23-20 \%$ \\
\hline 00 & 6,70 & 6,93 & 6,68 & 7,11 & 6,94 & 7,08 \\
\hline 50 & 6,62 & 6,82 & 7,34 & 7,72 & 6,89 & 7,18 \\
\hline 100 & 6,73 & 6,58 & 6,63 & 6,63 & 6,91 & 6,74 \\
\hline 150 & 6,51 & 6,88 & 6,74 & 6,95 & 7,03 & 6,75 \\
\hline 200 & 6,49 & 6,80 & 5,92 & 6,58 & 6,89 & 7,14 \\
\hline 250 & 6,49 & 6,54 & 6,46 & 6,40 & 7,53 & 6,92 \\
\hline 300 & 6,55 & 6,84 & 6,42 & 6,90 & 7,03 & 7,33 \\
\hline 350 & 6,08 & 6,87 & 7,60 & 6,83 & 8,44 & 8,35 \\
\hline Média & $6,52 \mathrm{a}$ & $6,78 b$ & $6,72 \mathrm{a}$ & $6,89 a$ & $7,21^{\mathrm{a}}$ & $7,19^{a}$ \\
\hline Efeito & ns & Ns & $\mathrm{Q}^{* *}$ & $\mathrm{~L}^{*}$ & $\mathrm{Q}^{*}$ & $\mathrm{Q}^{* *}$ \\
\hline $\mathrm{CV}(\%)$ & 7,92 & & 9,67 & & 10,29 & \\
\hline
\end{tabular}

Foi observado efeito linear $(\mathrm{P}<0,05)$ em relação aos teores de cálcio para as aves alimentadas com $23 \%$ de PB na fase inicial. Entretanto, o coeficiente de determinação foi baixo $\left(\mathrm{R}^{2}=\right.$
0,26), o que invalida inferências a respeito desse efeito. Também ocorreu efeito quadrático $(\mathrm{P}<0,01)$ em relação aos teores de cálcio para os tratamentos com $20 \%$ de PB na fase inicial. 
Olanrewaju et al. (2007) trabalharam com dietas para frangos de corte com dois níveis de BE (174 e $241 \mathrm{mEq} / \mathrm{kg}$ ) e verificaram maiores teores de cálcio e sódio no plasma sanguíneo das aves aos 35 dias de idade quando receberam a dieta com alto nível de BE, diferentes dos resultados obtidos no presente estudo, em que não houve aumento do cálcio sérico, em função do aumento dos níveis de $\mathrm{BE}$ da dieta.

Em relação ao nível sérico de proteína total, houve efeito quadrático $(\mathrm{P}<0,05$ e $\mathrm{P}<0,01)$ para as aves alimentadas com os planos nutricionais 20-20\% PB e 23-20\% PB, respectivamente. Takeara et al. (2010) não encontraram efeito significativo em relação ao teor proteico na composição percentual de vísceras+sangue em frangos de corte na fase de 12 a 22 dias de idade. Os autores avaliaram rações com diferentes níveis de lisina digestível.

Ressalta-se que, no presente estudo, as análises de proteína total foram realizadas exclusivamente no soro sanguíneo das aves, portanto não se podem fazer inferências em relação à composição das vísceras.

$\mathrm{Na}$ Tab. 5, apresentam-se as equações de regressão e os valores mínimos percentuais plasmáticos de cálcio e de proteína total, além do nível ótimo de BE expresso em $\mathrm{mEq} / \mathrm{kg}$, obtidos por equações de regressão polinomial.

Tabela 5. Equações do balanço eletrolítico para parâmetros sanguíneos de frangos de corte aos 42 dias

\begin{tabular}{lllll|c} 
Parâmetro & $\begin{array}{l}\text { Sequência } \\
\text { proteica }\end{array}$ & \multicolumn{1}{c}{ Equação } & $\mathrm{R}^{2}$ & \multicolumn{2}{c}{$\begin{array}{c}\text { Balanço } \\
\text { Mín } \\
\text { eletrolítico } \\
(\mathrm{mEq} / \mathrm{kg})\end{array}$} \\
\hline $\mathrm{Ca}$ & $20-20 \%$ & $\hat{\mathrm{Y}}=7,17-0,00923383^{\mathrm{ns}} \mathrm{X}+0,000026742^{* *} \mathrm{X}^{2}$ & 0,38 & 6,37 & 172,65 \\
& $23-20 \%$ & $\hat{\mathrm{Y}}=7,19-0,00168889 \mathrm{X}$ & 0,26 & - & - \\
Ptn & $20-20 \%$ & $\hat{\mathrm{Y}}=7,03-0,00418902^{* *} \mathrm{X}+0,0000207498^{*} \mathrm{X}^{2}$ & 0,70 & 6,82 & 100,94 \\
& $23-20 \%$ & $\hat{\mathrm{Y}}=7,25-0,00749593^{* *} \mathrm{X}+0,000028651^{* *} \mathrm{X}^{2}$ & 0,83 & 6,76 & 130,79 \\
\hline
\end{tabular}

Ptn = proteína plasmática total aos 42 dias.

${ }^{* *}$ Efeito significativo $(\mathrm{P}<0,01)$; ${ }^{*}$ efeito significativo $(\mathrm{P}<0,05)$.

O ótimo BE para o cálcio sanguíneo foi de $173 \mathrm{mEq} / \mathrm{kg}$ para as aves que receberam $20 \%$ de PB na fase inicial, correspondendo ao teor de cálcio de 6,37mg/dL. Entretanto, deve-se ressaltar que o coeficiente de determinação apresentou valor baixo $\left(\mathrm{R}^{2}=0,38\right)$.

Os ótimos BE para os teores de proteína total foram de 101 e $131 \mathrm{mEq} / \mathrm{kg}$, correspondendo aos teores proteicos de 6,75 e $6,82 \mathrm{mg} / \mathrm{dL}$, para as aves que receberam rações com 20 e $23 \%$ de $\mathrm{PB}$ na fase inicial, respectivamente.

Os valores médios obtidos para o cálcio sérico foram de 6,72 e $6,89 \mathrm{mg} / \mathrm{dL}$. Os níveis de cálcio no sangue foram menores aos 42 dias de idade do que os obtidos por Vieites et al. (2004), que estudaram frangos de corte Ross aos 21 dias. Pode-se supor que aos 42 dias os mecanismos de reabsorção e excreção iônicas exercidos pelos rins foram mais eficientes que aos 21 dias. Em função disso, as aves na fase inicial mobilizariam mais cálcio do osso para o sangue para utilizá-lo como função tamponante.
Os tratamentos com menores e maiores valores de BE apresentaram as maiores concentrações de cálcio no sangue, o que pode representar maior mobilização óssea desse mineral por ação hormonal, com a finalidade de disponibilizar mais eletrólitos no sangue para serem utilizados por mecanismos compensatórios de regulação no organismo das aves.

Os níveis proteicos estudados não influenciaram os valores de BE para nenhum dos minerais avaliados, demonstrando que apenas o excesso de cloro ou potássio influenciou o equilíbrio ácido-base. As aves apresentaram menor percentual sanguíneo com balanços na faixa de 100 a $300 \mathrm{mEq} / \mathrm{kg}$. Isto pode ser explicado pela função exercida pelas proteínas plasmáticas em manter a pressão coloidosmótica do plasma. A hipoproteinemia está frequentemente associada ao edema, pois a pressão osmótica produzida por essas proteínas opõe-se à pressão hidrostática do sangue nos capilares e, dessa forma, evita o excesso de passagem de água para os tecidos (Swenson, 2006). Além disso, a concentração de cálcio total no plasma também é influenciada pela concentração de proteínas, pois um terço do 
cálcio circulante está associado a essas macromoléculas, principalmente a albumina (González et al., 2001).

Os resultados obtidos evidenciam a função exercida pelas proteínas séricas em manter a pressão coloidosmótica do plasma. Segundo Macari et al. (2002), quando há distúrbio do equilíbrio ácido-base, provocando alcalose ou acidose metabólica, ocorre ação tamponante dessas proteínas, captando ou doando íons $\mathrm{H}^{+}$por meio de seus terminais carboxílicos $(\mathrm{COOH}$ ou $\mathrm{COO}^{-}$), na tentativa de restabelecer o $\mathrm{pH}$ sanguíneo normal. Provavelmente, esta foi uma das razões de terem sido encontrados teores de proteína mais elevados para os tratamentos com valores altos e baixos de BE. Os maiores percentuais proteicos foram obtidos com $\mathrm{BE}$ de $350 \mathrm{mEq} / \mathrm{kg}$.

Embora tenham sido encontrados níveis de $101 \mathrm{e}$ $131 \mathrm{mEq} / \mathrm{kg}$, respectivamente, para os planos nutricionais $20-20 \%$ e $23-20 \%$ de PB, como aqueles determinantes do menor teor de proteína total no sangue, recomenda-se o nível de $175 \mathrm{mEq} / \mathrm{kg}$, que representa a média dos níveis de $\mathrm{BE}$ estudados para a manutenção da relação cálcio e fósforo no plasma e nível ótimo de proteínas para frangos de corte aos 42 dias de idade. Segundo Vargas Júnior et al. (2003), o cálcio e o fósforo apresentam uma proporção constante, de modo que o desequilíbrio desta possa afetar suas funções no organismo animal.

Ressalta-se que tal nível é recomendado para as condições ambientais registradas no presente estudo - umidade relativa média de $73 \%$ e médias de temperaturas mínimas e máximas de 21 e $29^{\circ} \mathrm{C}$, respectivamente -, que são típicas da estação de verão na Zona da Mata mineira, onde foi realizado o experimento. As respostas das características estudadas neste experimento poderiam ser diferentes em função das variáveis ambientais e do microclima presente no interior dos galpões de criação. As características sanguíneas avaliadas poderiam ser alteradas em condições de calor excessivo ou frio intenso, uma vez que o BE da dieta afeta os parâmetros fisiológicos dos frangos, que são importantes para a manutenção de sua homeostasia. Nos estudos de Mendes et al. (2004), frangos machos, selecionados para alta taxa de crescimento, apresentam aumento na viscosidade do sangue, principalmente quando submetidos a ambientes de baixa temperatura.

\section{CONCLUSÕES}

Os valores de balanço eletrolítico (BE) estimados para o menor valor de proteína total no sangue foram de 101 e $131 \mathrm{mEq} / \mathrm{kg}$ de ração, para planos nutricionais de $20-20 \%$ e $23-20 \%$ de proteina bruta, respectivamente. Não foram encontradas diferenças significativas para os teores plasmáticos de cálcio e fósforo entre os níveis de BE estudados.

\section{AGRADECIMENTO}

Ao Conselho Nacional de Desenvolvimento Científico e Tecnológico (CNPq), pela concessão da bolsa de estudos.

\section{REFERÊNCIAS BIBLIOGRÁFICAS}

BORGES, S.A.; MAIORKA, A.; SILVA, A.V.F. Fisiologia do estresse calórico e a utilização de eletrólitos em frangos de corte. Cienc. Rural. v.33, p.975-981, 2003.

GONZÁLES, F.H.D.; HAIDA, K.S.; MAHL, D. et al. Incidências de doenças metabólicas em frangos de corte no Sul do Brasil e uso do perfil bioquímico sanguíneo para seu estudo. Rev. Bras. Cienc. Avic., v.3, p.141-147, 2001.

MACARI, M.; FURLAN, R.L.; GONZALEZ, E. Fisiologia aviária aplicada a frangos de corte. Jaboticabal, SP: FUNEP/UNESP, 2002. 375p.

McDOWELL, L.R. Calcium and phosphorusminerals in animal and human nutrition. San Diego: Academic, 1992. p.26-77.

MENDES, A.A.; NAAS, I.A.; MACARI, M. Produção de frangos de corte. Campinas, SP: Facta - Fundação APINCO de Ciência e Tecnologia Avícola, 2004. 356p.

MONGIN, P. Recent advances in dietary anioncation balance: application in poultry. Proc. Nutr. Soc., v.40, p.285-294, 1981.

OLANREWAJU, H.A.; THAXTON, J.P.; DOZIER III, W.A. et al. Electrolyte diets, stress, and acid-base balance in broiler chickens. Poult. Sci., v.86, p.1363-1371, 2007. 
PATIENCE, J.F. A review of the role acid-base balance in amino acid nutrition. J. Anim. Sci., v.68, p.398-408, 1990.

ROSTAGNO, H.S. Tabelas brasileiras para aves e suínos: Composição de alimentos e exigências nutricionais. Viçosa, MG: UFV, 2000. 141p.

SWENSON, M.J. Dukes - Fisiologia dos animais domésticos. 12.ed. Rio de Janeiro: Guanabara Koogan, 2006. 946p.

TAKEARA, P.; TOLEDO, A.L.; GANDRA, E.R.S. et al. Lisina digestível para frangos de corte machos entre 12 e 22 dias de idade. Arq. Bras. Med. Vet. Zootec., v.62, p.1455 - 1461, 2010.
SISTEMA para análises estatísticas e genéticas, Versão 7.0. Viçosa, MG: UFV, 1997. 59p.

VARGAS JÚNIOR, J.G.; ALBINO, L.F.T.; ROSTAGNO, H.S. et al. Níveis nutricionais de cálcio e fósforo disponível para aves de reposição leves e semipesadas de 0 a 6 semanas de idade. Rev. Bras. Zootec., v.32, supl. 2, p.1919-1926, 2003.

VIEITES, F.M; MORAES, G.H.K; ALBINO, L.F.T. et al. Balanço eletrolítico e níveis de proteína bruta sobre o desempenho de pintos de corte de 1 a 21 dias de idade. Rev. Bras. Zootec., v.33, supl. 2, p.2076-2085, 2004. 